\title{
Impact of population admixture on the distribution of immune response co-stimulatory genes polymorphisms in a Brazilian population
}

\section{Gustavo Capatti Cassiano ${ }^{\mathrm{a}, \mathrm{b}, *}$, Eduardo José Melo Santos ${ }^{\mathrm{c}}$, Maria Helena Thomaz Maia ${ }^{\mathrm{c}}$, Adriana da Cruz Furini ${ }^{b}$, Luciane Moreno Storti-Melo ${ }^{d}$, Franciele Maira Batista Tomaz ${ }^{b}$, Pamella Cristina Alves Trindade ${ }^{\mathrm{b}}$, Marcela Petrolini Capobianco ${ }^{\mathrm{a}, \mathrm{b}}$, Marcos Antônio Trindade Amador ${ }^{\mathrm{e}}$, Giselle Maria Rachid Viana ${ }^{\mathrm{f}}$, Marinete Marins Póvoa ${ }^{\mathrm{f}}$, Sidney Emanuel Batista Santos ${ }^{\mathrm{e}}$, Ricardo Luiz Dantas Machado a,f}

${ }^{a}$ Universidade Estadual Paulista, Instituto de Biociências, Letras e Ciências Exatas, São José do Rio Preto, Brazil

${ }^{\mathrm{b}}$ Faculdade de Medicina de São José do Rio Preto, Centro de Investigação de Microrganismos, São José do Rio Preto, Brazil

${ }^{\mathrm{c}}$ Universidade Federal do Pará, Instituto de Ciências Biológicas, Belém, Brazil

${ }^{\mathrm{d}}$ Universidade Federal do Sergipe, Departamento de Biologia, Aracaju, Brazil

e Universidade Federal do Pará, Laboratório de Genética Humana e Médica, Belém, Brazi

${ }^{\mathrm{f}}$ Laboratório de Pesquisas Básicas em Malária, Instituto Evandro Chagas, Secretaria de Vigilância em Saúde, Ananindeua, Brazil

\section{A R T I C L E I N F O}

\section{Article history:}

Received 15 April 2014

Revised 8 September 2014

Accepted 27 September 2015

Available online 30 September 2015

\section{Keywords:}

Admixture population

Ancestry markers

Immunogenetics

\begin{abstract}
A B S T R A C T
Co-stimulatory molecules are essential in the orchestration of immune response and polymorphisms in their genes are associated with various diseases. However, in the case of variable allele frequencies among continental populations, this variation can lead to biases in genetic studies conducted in admixed populations such as those from Brazil. The aim of this study was to evaluate the influence of genomic ancestry on distributions of co-stimulatory genes polymorphisms in an admixed Brazilian population. A total of 273 individuals from the north of Brazil participated in this study. Nine single nucleotide polymorphisms in 7 genes (CD28, CTLA4, ICOS, CD86, CD40, CD40L and BLYS) were determined by polymerase chain reaction-restriction fragment length polymorphism. We also investigated 48 insertion/deletion ancestry markers to characterize individual African, European and Amerindian ancestry proportions in the samples. The analysis showed that the main contribution was European (43.9\%) but also a significant contribution of African (31.6\%) and Amerindian (24.5\%) ancestry. ICOS, CD40L and CD86 polymorphisms were associated with genomic ancestry. However there were no significant differences in the proportions of ancestry for the other SNPs and haplotypes studied. Our findings reinforce the need to apply AIMs in genetic association studies involving these polymorphisms in the Brazilian population.

(c) 2015 American Society for Histocompatibility and Immunogenetics. Published by Elsevier Inc. All rights
\end{abstract} reserved.

\section{Introduction}

The development of an immune response depends on a complex network of cells and is essential to protect humans against infectious agents and the appearance of autoimmune diseases and tumors. T cells have a critical role in the development of the immune response however these cells require two independent signals for them to become completely activated. The first signal is triggered by the binding of the $\mathrm{T}$ cell receptor (TCR) to an

\footnotetext{
* Corresponding author at: Departamento de Doenças Dermatológicas, Infeciosas e Parasitárias, Faculdade de Medicina de São José do Rio Preto, Avenida Brigadeiro Faria Lima, 5416, São José do Rio Preto, Brazil.

E-mail address: gcapatti@hotmail.com (G.C. Cassiano).
}

antigenic peptide presented by a major histocompatibility complex molecule (MHC). The second signal is provided by co-stimulatory molecules; the binding of the CD28 receptor to CD80 and CD86 molecules is essential for the activation of $\mathrm{T}$ cells. However, another molecule called CTLA-4 can also bind to CD80 and CD86 molecules which, instead to providing a positive stimulation, exert a regulatory role by reducing the generated response. This process is crucial for homeostasis and immune tolerance [1].

Another stimulatory receptor expressed on the surface of T cells is called ICOS; the gene of this molecule is located close to the CD28 and CTLA4 genes in the $2 \mathrm{q} 33$ chromosomal region. The interactions between B cells and activated T cells, mediated by CD40/CD40L signaling, also indirectly acts on $\mathrm{T}$ cell activation, but this signaling 
pathway is critical to B lymphocyte activation and so, in the development of the humoral immune response. Another molecule, BLyS, expressed on the surface of T cells and also in soluble form, modulates the survival and proliferation of $B$ cells through three different receptors: BR3, TACI and BCMA [2].

An adequate immune response must maintain a balance between the ability to respond to infectious agents and to suppress autoimmunity. Thus, polymorphisms associated with the modulation of gene expression of co-stimulatory molecules can influence the development of several diseases. In recent years, several studies have shown associations between polymorphisms in costimulatory genes and diseases [3-14]. However, studies in different populations have failed to reproduce the results [15-19]. One of the reasons may be due to variable allele frequencies in different populations, which result in a lack of statistical power. For example, geographical gradients in the distribution of CTLA4 alleles have been well documented [20]. Population structure also has been presumed to cause many of the unreplicated disease-marker associations reported in the literature, particularly in admixed populations.

Brazil has one of the most diverse populations in the world resulting from five centuries of interethnic breeding between Europeans, Africans and Amerindians. It has been shown that due to the intense miscegenation of the Brazilian population, indicators of physical appearance, such as skin color, are poor indicators of genomic ancestry $[21,22]$. Some studies have shown that the distribution of pharmacogenetic polymorphisms in the Brazilian population is best characterized using ancestry informative markers (AIMs) instead of self-declaration of ethnicity [23,24]. In fact, nowadays it is recognized that ethnicity can be better studied with AIMs, which enable a better understanding of the relationship between the various ethnic components and the variability of these co-stimulatory genes. Thus, the objective of the present study was to describe the allele frequencies of nine SNPs distributed across seven co-stimulatory genes (CD28, CTLA4, ICOS, CD86, CD40, CD40L and BLYS) and assess the impact of Brazilian population admixture on the distribution of these polymorphisms using AIMs.

\section{Materials and methods}

\subsection{Sample}

The sample of this study was composed of 273 ( 175 men and 91 women) unrelated subjects from the town of Goianésia do Pará $\left(03^{\circ} 50^{\prime} 33^{\prime \prime} \mathrm{S} ; 49^{\circ} 05^{\prime} 49^{\prime \prime} \mathrm{W}\right)$, located in the southeastern region of the State of Pará in the north of Brazil. All the participants signed informed consent forms. The project was approved by the Research Ethics Committee of the Medicine School in São José do Rio Preto (FAMERP 45992011). The DNA was extracted from peripheral blood samples using the Easy-DNA ${ }^{\mathrm{TM}}$ extraction kit (Invitrogen, California, USA).

\subsection{Genotyping}

The following SNPs were genotyped by polymerase chain reaction-restriction fragment length polymorphism (PCR-RFLP): rs35593994 and rs3116496 in the CD28 gene; rs5742909 and rs231775 in the CTLA4 gene; rs4404254 in the ICOS gene; rs1129055 in the CD86 gene; rs3092945 in the CD40L gene; rs1883832 in the CD40 gene and; rs9514828 in the BLYS gene. All PCR reactions were performed in a final volume of $25 \mu \mathrm{L}$ containing $1 \times$ Buffer (20 mM Tris- $\mathrm{HCl} \mathrm{pH} \mathrm{8.4,} 50 \mathrm{mM} \mathrm{KCl}$ ), $1.5 \mathrm{mM} \mathrm{MgCl}_{2}$, $0.2 \mathrm{mM}$ of each dNTP, $0.4 \mathrm{pmol}$ of each primer and $0.5 \mathrm{U}$ of Taq DNA Polymerase Platinum (Invitrogen, São Paulo, Brazil). Amplifications were made in a MasterCycler DNA thermal cycler (Eppendorf, Hamburg, Germany) under the following conditions: an initial step of 5 min at $94{ }^{\circ} \mathrm{C}, 35$ cycles of $30 \mathrm{~s}$ at $94^{\circ} \mathrm{C}, 30 \mathrm{~s}$ at an annealing temperature depending on the primer and $1 \mathrm{~min}$ at $72{ }^{\circ} \mathrm{C}$, and a final step of $10 \mathrm{~min}$ at $72{ }^{\circ} \mathrm{C}$. The sequences of the primers as well as the annealing temperatures used in each reaction are shown in Table 1 . The amplification products were viewed in agarose gel

Table 1

Location of SNPs, primers, annealing temperatures, restriction enzymes used for genotyping and length of fragments resulting from PCR-RFLP.

\begin{tabular}{|c|c|c|c|c|c|c|c|}
\hline SNP & $\begin{array}{l}\text { Gene } \\
\text { (Chromosome } \\
\text { region) }\end{array}$ & Location & Primer $5^{\prime}-3^{\prime}$ (forward) & Primer $5^{\prime}-3^{\prime}$ (reverse) & $\begin{array}{l}\text { Annealing } \\
\text { temperature } \\
\left({ }^{\circ} \mathrm{C}\right)\end{array}$ & $\begin{array}{l}\text { Restriction } \\
\text { enxyme }\end{array}$ & $\begin{array}{l}\text { Fragments } \\
\text { length (pb) }\end{array}$ \\
\hline rs35593994 & CD28 (2q33) & 204570826 & TTCTCATTCTGTTGCCCTGGC & CACCATCCCCTTAGGGCACAT & 62 & Hinfl & $\begin{array}{l}\text { G: } 468+78 \\
\text { A: } 546\end{array}$ \\
\hline rs3116496 & CD28 (2q33) & 204594512 & GAAACACCTTTGTCCAAGTC & CTCAATGCCTTCTGGGAAATC & 52 & Acil & $\begin{array}{l}\mathrm{T}: 333 \\
\mathrm{C}: 193+140\end{array}$ \\
\hline rs5742909 & CTLA4 (2q33) & 204732347 & GGGATTTAGGAGGACCCTTG & GTGCACACACAGAAGGCACT & 48 & MseI & $\begin{array}{l}\text { C: } 244 \\
\text { T: } 179+65\end{array}$ \\
\hline rs231775 & CTLA4 (2q33) & 204732714 & CTGAACACCGCTCCCATAAA & CACTGCCTTTGACTGCTGAA & 50 & BbvI & $\begin{array}{l}\text { A: } 215 \\
\text { G: } 159+56\end{array}$ \\
\hline rs4404254 & $\operatorname{ICOS}(2 \mathrm{q} 33)$ & 204819570 & TTACCAAGACTTTAGATGCTTTCTT & GAATCTTTCTAGCCAAATCATATTC & 55 & AluI & $\begin{array}{l}\text { T: } 385+339 \\
+99 \\
\text { C: } 339+289 \\
+99+96\end{array}$ \\
\hline rs1129055 & $C D 86(3 q 21)$ & 121838319 & CTGTTCCAATGGCAACCTCT & GGTTGCCCAGGAACTTACAA & 56 & CviKI-1 & $\begin{array}{l}\text { G: } 79+75 \\
+58+54 \\
\text { A: } 154+58 \\
+54\end{array}$ \\
\hline rs3092945 & CD40L (Xq26) & 135729609 & ATCTTCACAGCAACCTAC & CACTAAACTCAATGAAAGCC & 56 & LweI & $\begin{array}{l}T: 251+195 \\
C: 446\end{array}$ \\
\hline rs1883832 & $\begin{array}{l}C D 40(20 \mathrm{q} 12- \\
\mathrm{q} 13.2)\end{array}$ & 44746982 & GAAACTCCTGCGCGGTGAAT & GAAACTCCTGCGCGGTGAAT & 56 & StyI & $\begin{array}{l}C: 133+96 \\
+74 \\
\text { T: } 207+96\end{array}$ \\
\hline rs9514828 & $\begin{array}{l}\text { BLYS (13q32- } \\
\text { q34) }\end{array}$ & 108921373 & TGGCTCTTGTGTGATCAAGG & GCCTGGTCTCAGCTTTTCTG & 50 & MbiI & $\begin{array}{l}\mathrm{C}: 162+48 \\
\mathrm{~T}: 210\end{array}$ \\
\hline
\end{tabular}

Chromosome positions were referred to the sequence of NCBI database (GRCh37). 
Table 2

Genotypic frequencies and proportion of the African, European and Amerindian ancestry according to genotype.

\begin{tabular}{|c|c|c|c|c|}
\hline Genotypes & Frequency (\%) & African $^{\mathrm{a}}$ & European $^{a}$ & Amerindian $^{\mathrm{a}}$ \\
\hline rs35593994 & $n=273$ & & & \\
\hline$G / G$ & 46.7 & $0.309(0.29-0.33)$ & $0.445(0.42-0.47)$ & $0.246(0.23-0.26)$ \\
\hline$G / A$ & 45.8 & $0.320(0.30-0.34)$ & $0.440(0.42-0.46)$ & $0.239(0.22-0.26)$ \\
\hline$A / A$ & 7.5 & $0.333(0.29-0.37)$ & $0.394(0.35-0.44)$ & $0.273(0.24-0.31)$ \\
\hline$p$ & & 0.54 & 0.2 & 0.33 \\
\hline rs3116496 & $n=273$ & & & \\
\hline$T / T$ & 65.0 & $0.317(0.30-0.33)$ & $0.434(0.42-0.45)$ & $0.248(0.23-0.26)$ \\
\hline$T / C$ & 32.0 & $0.311(0.29-0.33)$ & $0.453(0.43-0.48)$ & $0.235(0.21-0.26)$ \\
\hline$C / C$ & 3.0 & $0.349(0.27-0.42)$ & $0.380(0.28-0.48)$ & $0.271(0.18-0.37)$ \\
\hline$p$ & & 0.67 & 0.2 & 0.44 \\
\hline rs5742909 & $n=271$ & & & \\
\hline$C / C$ & 0.84 & $0.317(0.30-0.33)$ & $0.439(0.42-0.45)$ & $0.243(0.23-0.26)$ \\
\hline$C / T$ & 0.16 & $0.310(0.27-0.35)$ & $0.435(0.39-0.48)$ & $0.255(0.22-0.29)$ \\
\hline$p$ & & 0.91 & 0.95 & 0.93 \\
\hline rs231775 & $n=272$ & & & \\
\hline$A / A$ & 41.0 & $0.317(0.30-0.34)$ & $0.432(0.41-0.45)$ & $0.251(0.23-0.27)$ \\
\hline$A / G$ & 49.0 & $0.313(0.30-0.33)$ & $0.441(0.42-0.46)$ & $0.246(0.23-0.26)$ \\
\hline$G / G$ & 9.0 & $0.335(0.28-0.39)$ & $0.453(0.40-0.51)$ & $0.212(0.18-0.23)$ \\
\hline$p$ & & 0.65 & 0.68 & 0.17 \\
\hline rs4404254 & $n=269$ & & & \\
\hline$T / T$ & 44.4 & $0.301(0.28-0.32)$ & $0.447(0.42-0.47)$ & $0.252(0.23-0.27)$ \\
\hline$T / C$ & 42.3 & $0.314(0.29-0.33)$ & $0.445(0.42-0.47)$ & $0.240(0.22-0.26)$ \\
\hline$C / C$ & 13.3 & $0.371(0.33-0.41)$ & $0.394(0.36-0.43)$ & $0.235(0.20-0.27)$ \\
\hline$p$ & & 0.003 & 0.054 & 0.53 \\
\hline rs1129055 & $n=272$ & & & \\
\hline$G / G$ & 61.9 & $0.322(0.30-0.34)$ & $0.426(0.40-0.44)$ & $0.251(0.24-0.27)$ \\
\hline$G / A$ & 34.0 & $0.301(0.29-0.33)$ & $0.459(0.44-0.48)$ & $0.231(0.21-0.25)$ \\
\hline$A / A$ & 4.1 & $0.278(0.20-0.35)$ & $0.459(0.36-0.56)$ & $0.263(0.20-0.32)$ \\
\hline$p$ & & 0.34 & 0.09 & 0.2 \\
\hline rs1883832 & $n=272$ & & & \\
\hline$C / C$ & 73.6 & $0.319(0.30-0.33)$ & $0.436(0.42-0.45)$ & $0.245(0.23-0.26)$ \\
\hline$C / T$ & 22.6 & $0.301(0.28-0.33)$ & $0.450(0.42-0.48)$ & $0.241(0.22-0.27)$ \\
\hline$T / T$ & 3.8 & $0.301(0.22-0.40)$ & $0.434(0.38-0.50)$ & $0.258(0.21-0.31)$ \\
\hline$p$ & & 0.81 & 0.72 & 0.87 \\
\hline rs9514828 & $n=271$ & & & \\
\hline$C / C$ & 55.3 & $0.320(0.30-0.34)$ & $0.432(0.41-0.45)$ & $0.248(0.23-0.26)$ \\
\hline$C / T$ & 37.9 & $0.317(0.30-0.34)$ & $0.447(0.42-0.47)$ & $0.236(0.22-0.25)$ \\
\hline$T / T$ & 6.8 & $0.289(0.23-0.35)$ & $0.450(0.38-0.52)$ & $0.261(0.21-0.31)$ \\
\hline$p$ & & 0.54 & 0.60 & 0.47 \\
\hline \multicolumn{5}{|l|}{ rs3092945 } \\
\hline Women & $n=92$ & & & \\
\hline$T / T$ & 78.0 & $0.300(0.27-0.33)$ & $0.453(0.42-0.48)$ & $0.247(0.23-0.27)$ \\
\hline$T / C$ & 18.7 & $0.326(0.27-0.38)$ & $0.395(0.34-0.45)$ & $0.279(0.24-0.32)$ \\
\hline$C / C$ & 3.3 & $0.408(0.07-0.74)$ & $0.424(0.18-0.67)$ & $0.169(0.08-0.23)$ \\
\hline$p$ & & 0.22 & 0.18 & 0.10 \\
\hline Men & $n=180$ & & & \\
\hline$T$ & 90.0 & $0.314(0.30-0.33)$ & $0.446(0.43-0.46)$ & $0.240(0.22-0.26)$ \\
\hline C & 10.0 & $0.373(0.30-0.44)$ & $0.368(0.30-0.44)$ & $0.259(0.20-0.32)$ \\
\hline$p$ & & 0.02 & 0.008 & 0.42 \\
\hline
\end{tabular}

Bold value indicates $p<0.05$.

a Ancestry expressed as mean $(95 \% \mathrm{CI})$.

after staining with $2 \%$ GelRed $^{\mathrm{TM}}$ (Biotium, Hayward, USA) and were digested using enzymes of the Fermentas company (Vilnius, Lithuania) according to manufacturer's instructions. The enzymes used, as well as the size of the fragments resulting from the digestion of each polymorphism are shown in Table 1 . The digestion products were stained with $2.5 \%$ GelRed $^{\mathrm{TM}}$ (Biotium, Hayward, USA) and viewed in agarose gel with the exception of the rs1883832 and rs5742909 polymorphisms, which were viewed in $12.5 \%$ polyacrylamide gel after staining with ethidium bromide.

\subsection{Determination of ancestry}

Genotyping to determine ancestry was carried out using 48 INDEL-type markers (insertion/deletion) that have been standardized and validated [25]. The markers were selected employing two main criteria: significant differences in allele frequencies between Africans, Europeans and/or Amerindians ( $\geqslant 40 \%$ ) and located on different chromosomes or in distant physical regions when on the same chromosome. Estimation of the parental ancestry of the Brazilian samples was performed considering three parental populations, which was evaluated by Santos et al. [25]: Africans (from Angola, Mozambique, Zaire, Cameroon, and the Ivory Coast), Europeans (mainly Portuguese), and Native Americans (individuals from indigenous tribes of the Brazilian Amazon region). The PCR reactions were carried out on three multiplex systems, each one containing 16 pairs of fluorescent-labeled primers. Electrophoresis was carried out in an automatic sequencer (ABI PRISM 3130 Genetic Analyzer: Applied Biosystems). The sequences of the primers as well as the conditions of cycling and of capillary electrophoresis are described by Santos et al. [25]. 


\subsection{Statistical analysis}

The program Structure version 2.3.4 (http://pritch.bsd.uchicago. edu/software.html) was used to estimate the individual interethnic admixture. Allele and genotype frequencies for each variant were obtained using the genetics package [26]. Using this package, deviations from Hardy-Weinberg equilibrium were evaluated by the Chi-square test and the linkage disequilibrium between pairs of loci was analyzed using parameter $D^{\prime}$. Haplotype frequencies were estimated by the maximum likelihood method which uses the expectation-maximization algorithm which is part of the haplo. stats package [27]. Analysis of variance (ANOVA) and Student's t test were used to test differences in the proportions of each of the ancestries between different genotypes. A binary logistic regression model was built to graphically explore the association of polymorphisms with individual estimated ancestry using the ggplot2 package [28]. All packages were implemented employing the $\mathrm{R}$ computer program, version 2.11.1 (http:www.r-project. org). $P$-values $<0.05$ were considered statistically significant.

\section{Results}

\subsection{Distribution of polymorphisms according to ancestry}

The genotype frequencies of the nine SNPs studied are shown in Table 2. All polymorphisms are in Hardy-Weinberg equilibrium. Allele frequencies found in the current study, as well as in other geographical populations are presented in Supplementary Table 1.

Variance analysis used to test the difference of each ancestry between the different genotypes demonstrated that the mean proportions of African ancestry differed significantly between the genotypes of the rs4404254 SNP in the ICOS gene ( $p$ value $=0.003$ ). The Tukey post hoc test indicated that the mean African ancestry was higher for the CC genotype than for the TC $(p$-value $=0.01)$ and TT genotypes $(p$-value $=0.002)$. As the CD40L gene is on the X chromosome, analyses of the rs3092945 SNP in this gene were performed separately for men and women. The mean proportion of African ancestry was higher in men with the $C$ allele than those with the $T$ allele $(p$-value $=0.02)$. Moreover,
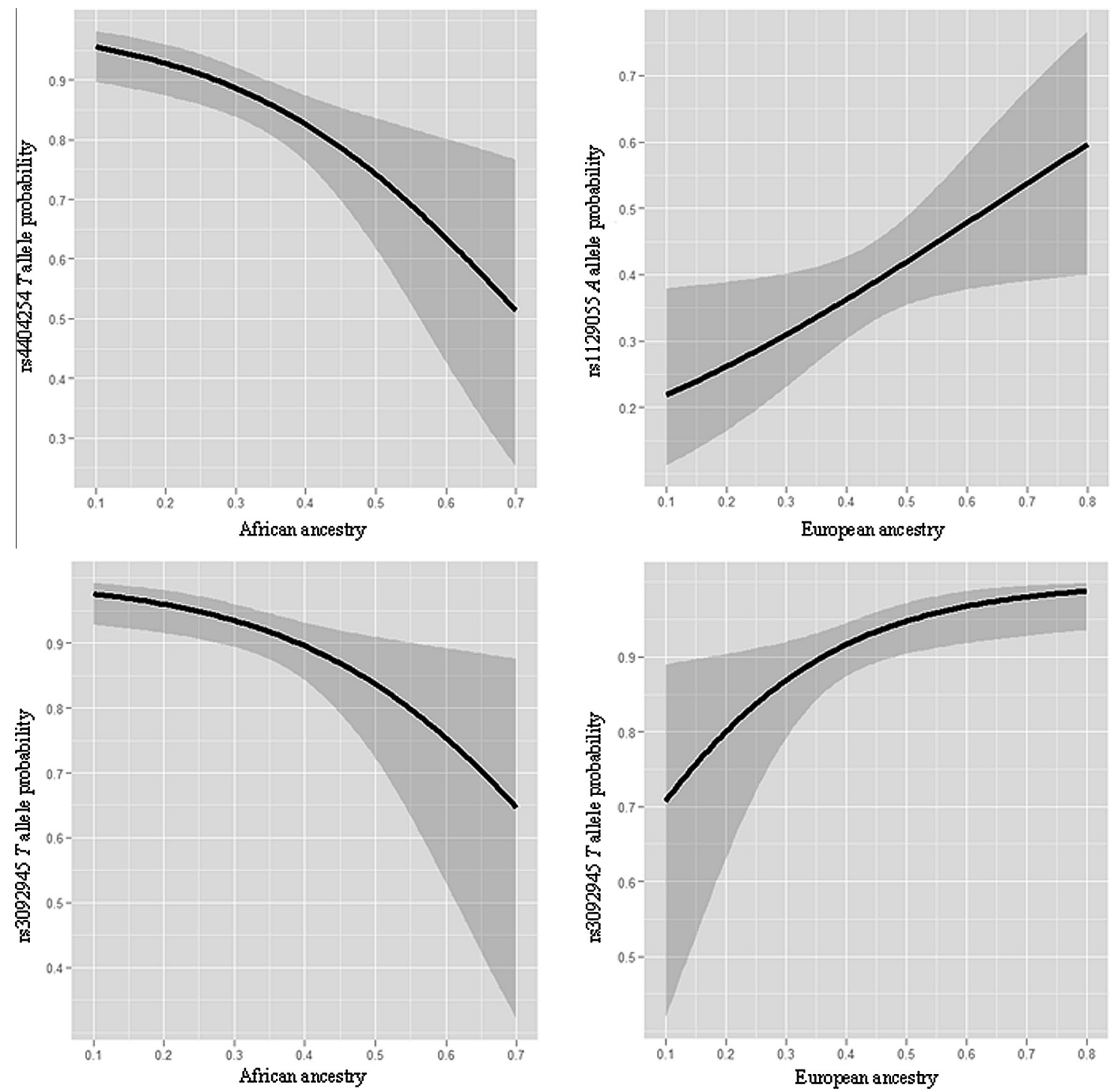

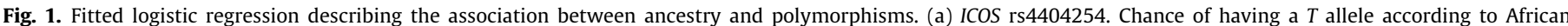

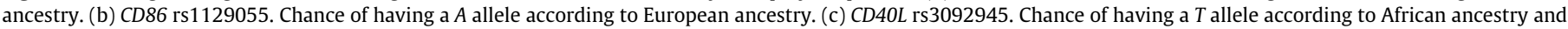
(d) according to European ancestry. Gray shadows show 95\% confidence intervals. Graphics were created using ggplot2 in R. 
men with the $T$ allele had a higher average proportion of European ancestry compared to men with the $C$ allele ( $p$-value $=0.008$ ). There were no significant differences in the proportions of ancestry for the other SNPs studied (Table 2).

Binary logistic regression, using the generalized linear model and implemented in the program $\mathrm{R}$, was employed to graphically explore the association between polymorphisms and ancestry. The results, presented in Fig. 1, show that the chance of having at least one $T$ allele for the rs3092945 of the CD40L gene continuously decreases as African ancestry increases ( $p$-value $=0.008$ ). Furthermore, the chance of having this allele increases as the European ancestry increases $(p$-value $=0.01)$. In relation to the rs4404254 SNP in the ICOS gene, the chance of having the $T$ allele decreases as African ancestry increases ( $p$-value $=0.001)$. The chance of an individual having the $A$ allele (rs1129055) in the $C D 86$ gene increases as the European ancestry increases ( $p$ value $=0.02$ )

\subsection{Linkage disequilibrium and haplotypes}

Linkage disequilibrium were evaluated using the statistical parameter $D^{\prime}$, between all pairs of SNPs in the CD28, CTLA4 and ICOS genes located in the chromosome 2q33 region. There was absolute linkage disequilibrium $\left(D^{\prime}\right)$ only between the rs35593994 and rs3116496 SNPs and between the rs35593994 and rs5742909 SNPs. The value of $D^{\prime}$ varied for the other pairs of SNPs (Supplementary Table 2).

Eighteen haplotypes of the CD28, CTLA4 and ICOS genes were found in the study sample with frequencies ranging from 0.002 to 0.194 (Table 3 ). The haplo.stats computer program whose function haplo.score generates a score for each haplotype (hap.score), as well as a p-value for each hap.score was used to assess whether a given haplotype is associated with differences in the proportions of ancestry. A positive/negative score for a given haplotype suggest that the haplotype is associated with an increase/decrease in ancestry. Only haplotypes with frequencies higher than 0.01 were included in the analysis. The GTCGT, GTCGC and ATCGC haplotypes had significant associations with African ancestry, and the GTCGT haplotype presented a significant association with European ancestry. However,

Table 3

Haplotype frequencies and association with African, European and Amerindian ancestry.

\begin{tabular}{|c|c|c|c|c|c|c|c|}
\hline \multirow[b]{2}{*}{ Haplotype $^{\mathrm{a}}$} & \multirow[b]{2}{*}{ Frequency $^{\mathrm{b}}$} & \multicolumn{2}{|c|}{ African } & \multicolumn{2}{|c|}{ European } & \multicolumn{2}{|c|}{ Amerindian } \\
\hline & & $\begin{array}{l}\text { hap. } \\
\text { score }^{c}\end{array}$ & $p$ & $\begin{array}{l}\text { hap. } \\
\text { score }^{\mathrm{c}}\end{array}$ & $p$ & $\begin{array}{l}\text { hap. } \\
\text { score }^{c}\end{array}$ & $p$ \\
\hline GTCGT & 0.193 & -2.06 & 0.03 & 2.18 & 0.02 & -0.29 & 0.77 \\
\hline GTCAT & 0.153 & -1.64 & 0.09 & 0.46 & 0.64 & 1.37 & 0.17 \\
\hline ATCAT & 0.136 & -1.13 & 0.25 & 0.17 & 0.85 & 1.09 & 0.27 \\
\hline GTCAC & 0.102 & 1.08 & 0.27 & -0.66 & 0.50 & -0.43 & 0.66 \\
\hline ATCAC & 0.098 & 1.92 & 0.05 & -1.71 & 0.08 & 0.01 & 0.98 \\
\hline GCTAT & 0.055 & -0.98 & 0.32 & 0.03 & 0.97 & 1.11 & 0.26 \\
\hline GTCGC & 0.051 & 2.26 & 0.02 & -1.07 & 0.28 & -1.41 & 0.15 \\
\hline GCCAT & 0.050 & 1.15 & 0.24 & -0.55 & 0.58 & -0.69 & 0.48 \\
\hline GCCAC & 0.044 & -0.29 & 0.77 & 0.44 & 0.65 & -0.24 & 0.80 \\
\hline ATCGT & 0.032 & 0.07 & 0.93 & 0.16 & 0.87 & -0.26 & 0.78 \\
\hline ATCGC & 0.027 & 2.57 & 0.01 & -1.62 & 0.10 & -0.92 & 0.35 \\
\hline GCCGT & 0.024 & 0.50 & 0.61 & 0.62 & 0.53 & -1.30 & 0.19 \\
\hline GTTAT & 0.008 & - & - & - & - & - & - \\
\hline GCTAC & 0.007 & - & - & - & - & - & - \\
\hline ATTAC & 0.006 & - & - & - & - & - & - \\
\hline ACTGC & 0.002 & - & - & - & - & - & - \\
\hline ATTGC & 0.002 & - & - & - & - & - & - \\
\hline GCCGC & 0.002 & - & - & - & - & - & - \\
\hline
\end{tabular}

a Order of variants in haplotype is as follows rs35593994, rs3116496, rs5742909, rs231775, rs4404254.

b Estimated frequency of each haplotype in the population.

c The score for the haplotype, which is the statistical measurement of association of each specific haplotype with the trait.

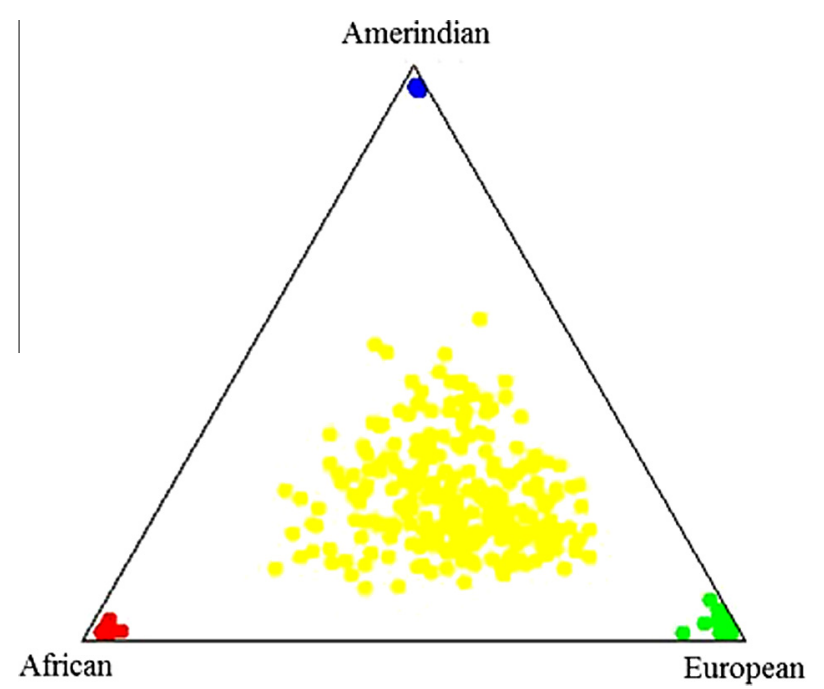

Fig. 2. Schematic representation of the individual admixture estimates. Each point represents one individual and the correspondent admixture proportions are indicated by the distance to the edges of the triangle. European, African and Amerindian correspond to individuals from the parental populations. The figure was made using Structure v. 2.3.4 software.

when the Bonferroni correction was applied (corrected $p$-value $<0.004$ ), these differences were no longer significant.

\subsection{Estimate of ancestry}

The genotypes of the sample population from Goianésia do Pará and parental populations (Europeans, Africans and Amerindians) were analyzed together, assuming $K=3$. The analysis showed that the study sample is composed of individuals who possess an average of $43.9 \%$ European ancestry (ranging from $16.2 \%$ to $70.5 \%$ ), $31.6 \%$ African (ranging from $11.4 \%$ to $66.4 \%$ ) and $24.5 \%$ Amerindian (ranging from $8.3 \%$ to $57.3 \%$ ). The results are shown in Fig. 2. There were no significant differences in the proportions of genomic ancestry between males and females (Mann-Whitney test, all $p$ value $>0.14$ ).

\section{Discussion}

Analysis using AIMs demonstrates that the population of Goianésia do Pará, a town located in the north of Brazil, presents greater contribution from European ancestry (43.9\%), and smaller, albeit significant, contributions from African and Amerindian ancestries (31.6\% and $24.5 \%$, respectively). These values are similar to other Brazilian populations, although the proportion of African ancestry in this study was higher than other populations of the northern region of Brazil with contributions ranging from $12 \%$ to $25 \%[25,29,30]$. This variation might be explained by the large presence of individuals from the northeastern region of Brazil in the studied population, where the contribution of African ancestry is admittedly greater than in other regions of Brazil [21].

We report that ICOS, CD40L, and CD86 polymorphisms were associated with genomic ancestry. In fact, according to available data from 1000Genomes project, the $T$ allele frequency for rs4404254 SNP in the ICOS gene is lower in populations of African origin [31]. The rs3092945 SNP is also significantly associated with ancestry; the $T$ allele frequency has a reverse relationship with African ancestry and its frequency increases with the increase in European ancestry. These observations are consistent with available data which show a lower prevalence of this allele in African populations compared to Europeans, specifically Italians and Iberians, who were the largest source of Brazilian immigration [31]. 
Using a logistic regression model, we showed that the chance of an individual possessing the $A$ allele for rs1129055 SNP in the CD86 gene is enhanced with the increase in European ancestry. This polymorphism has often been assessed in studies of associations with autoimmune diseases and cancer in Asian populations [3234], but information about the frequency of this SNP in other populations are scarce. Our results are in accordance with data which report a higher frequency of the allele in the European population compared to an African population [31]. Beltrame et al. [35] evaluated this polymorphism in populations of different ancestries and found that the $G$ allele is more common, with the exception of the Japanese population, where an inversion of the allele frequencies exists with the $A$ allele being the most prevalent. As some Amerindian groups have lower frequencies of the $A$ allele, the authors suggest that this change in allele frequencies occurred recently on the Asian continent. Although the frequency of the allele is lower in Amerindian populations, we found no significant association in respect to this allele with Amerindian ancestry.

We found no association of ancestry with the other evaluated SNPs. Previous studies on the Brazilian population compared allele frequencies of polymorphisms between Euro-and Afro-Brazilians (Supplementary Table 1). Differences were only found with the rs3116496 and rs1883832 SNPs [36,37]; this is not in accordance with our results. These differences may be due to the fact that in these studies, the classification of Euro- and Afro-Brazilians was performed using morphological features and/or self-declaration of ethnicity, indicators that have been demonstrated as poor to describe genomic ancestry $[21,22]$. However, differences in allele frequencies of these two SNPs, as well as the rs9514828 SNP in the gene BLYS are evident when the 1000Genomes data are assessed. Hence, it is possible that these populations differ in their allele frequencies compared to the parental populations that formed the population of Goianésia do Pará, which could thus explain the absence of any association of these polymorphisms with ancestry in our study.

The tests of associations between ancestry and haplotypes showed no significant effect of the stratification of the population on the distribution of haplotypes. This corroborates the study of Pincerati et al. [38], who also found no significant differences in the frequencies in the haplotype frequencies of the CD28 and CTLA4 genes between Euro- and Afro-Brazilians. Although Butty et al. [39] demonstrated differences in the distribution of haplotypes of the CD28, CTLA4 and ICOS genes between different geographical populations, the intense process of miscegenation of the Brazilian population may have eliminated patterns of linkage disequilibrium in parental populations and changed the haplotype frequencies.

Information on genotype and allele frequencies, as well as estimates of haplotype frequencies and their associations with the levels of ancestry are fundamental in mixed populations, since the population structure can lead to spurious results in genetic association studies. In this study we describe the association of SNPs in ICOS, CD40L, and CD86 genes with ancestry in the Brazilian population. Our findings reinforce the need to apply AIMs in genetic association studies involving these polymorphisms in the Brazilian population.

\section{Conflict of interest}

The authors declare no conflict of interest.

\section{Acknowledgments}

To David Andrew Hewitt for the English revision of this manuscript. Financial support was provided by National Counsel of Technological and Scientific Development (CNPq, proc. 471605/2011-5).

\section{Appendix A. Supplementary material}

Supplementary data associated with this article can be found, in the online version, at http://dx.doi.org/10.1016/j.humimm.2015. 09.045.

\section{References}

[1] Greenwald RJ, Freeman GJ, Sharpe AH. The B7 family revisited. Annu. Rev. Immunol. 2005;23:515-48.

[2] Scholz JL, Oropallo MA, Sindhava V, Goenka R, Cancro MP. The role of B lymphocyte stimulator in B cell biology: implications for the treatment of lupus. Lupus 2013;22:350-60.

[3] Benmansour J, Stayoussef M, Al-Jenaidi FA, Rajab MH, Rayana CB, Said HB, Mahjoub T, Almawi WY. Association of single nucleotide polymorphisms in cytotoxic T-lymphocyte antigen 4 and susceptibility to autoimmune type 1 diabetes in Tunisians. Clin. Vaccine Immunol. 2010;17:1473-7.

[4] Si X, Zhang X, Tang W, Luo Y. Association between the CTLA-4 +49A/G polymorphism and Graves' disease: a meta-analysis. Exp. Ther. Med. 2012;4:538-44

[5] Li X, Zhang C, Zhang J, Zhang Y, Wu Z, Yang L, Xiang Z, Qi Z, Zhang X, Xiao X. Polymorphisms in the CTLA-4 gene and rheumatoid arthritis susceptibility: a meta-analysis. J. Clin. Immunol. 2012;32:530-9.

[6] Dalla-Costa R, Pincerati MR, Beltrame MH, Malheiros D, Petzl-Erler ML. Polymorphisms in the $2 q 33$ and $3 q 21$ chromosome regions including T-cell coreceptor and ligand genes may influence susceptibility to pemphigus foliaceus. Hum. Immunol. 2010;71:809-17.

[7] Song GG, Lee YH. The CTLA-4 and MCP-1 polymorphisms and susceptibility to systemic sclerosis: a meta-analysis. Immunol. Invest. 2013:42:481-92.

[8] Hughes T, Adler A, Kelly JA, Kaufman KM, Williams AH, Langefeld CD, Brown EE, Alarcón GS, Kimberly RP, Edberg JC, Ramsey-Goldman R, Petri M, Boackle SA, Stevens AM, Reveille JD, Sanchez E, Martín J, Niewold TB, Vilá LM, Scofield RH, Gilkeson GS, Gaffney PM, Criswell LA, Moser KL, Merrill JT, Jacob CO, Tsao BP, James JA, Vyse TJ, Alarcón-Riquelme ME, BIOLUPUS Network, Harley JB, Richardson BC, Sawalha AH. Evidence for gene-gene epistatic interactions among susceptibility loci for systemic lupus erythematosus. Arthritis Rheum. 2012;64:485-92.

[9] Sokolova EA, Malkova NA, Korobko DS, Rozhdestvenskii AS, Kakulya AV, Khanokh EV, Delov RA, Platonov FA, Popova TY, Aref' eva EG, Zagorskaya NN, Alifirova VM, Titova MA, Smagina IV, El' chaninova SA, Popovtseva AV, Puzyrev VP, Kulakova OG, Tsareva EY, Favorova OO, Shchur SG, Lashch NY, Popova NF, Popova EV, Gusev EI, Boyko AN, Aulchenko YS, Filipenko ML. Association of SNPs of CD40 gene with multiple sclerosis in Russians. PLoS One 2013;8: e61032.

[10] Nieters A, Bracci PM, de Sanjosé S, Becker N, Maynadié M, Benavente Y, Foretova L, Cocco P, Staines A, Holly EA, Boffetta P, Brennan P, Skibola CF. A functional TNFRSF5 polymorphism and risk of non-Hodgkin lymphoma, a pooled analysis. Int. J. Cancer 2011;128:1481-5.

[11] Pineda B, Tarín JJ, Hermenegildo C, Laporta P, Cano A, García-Pérez MÁ. Gene interaction between CD40 and CD40L reduces bone mineral density and increases osteoporosis risk in women. Osteoporos. Int. 2011:221451-8.

[12] Sabeti P, Usen S, Farhadian S, Jallow M, Doherty T, Newport M, Pinder M, Ward R, Kwiatkowski D. CD40L association with protection from severe malaria. Genes Immun. 2002;3:286-91.

[13] Manjurano A, Clark TG, Nadjm B, Mtove G, Wangai H, Sepulveda N, Campino SG, Maxwell C, Olomi R, Rockett KR, Jeffreys A, MalariaGen Consortium, Riley EM, Reyburn H, Drakeley C. Candidate human genetic polymorphisms and severe malaria in a Tanzanian population. PLoS One 2012;7:e47463.

[14] Zayed RA, Sheba HF, Abo Elazaem MA, Elsaadany ZA, Elmessery LO, Mahmoud JA, Abdel Rahman DR, Abdou FR. B-cell activating factor promoter polymorphisms in egyptian patients with systemic lupus erythematosus. Ann. Clin. Lab. Sci. 2013;43:289-94.

[15] Buck D, Kroner A, Rieckmann P, Mäurer M, Wiendl H. Analysis of the C/T(-1) single nucleotide polymorphism in the CD40 gene in multiple sclerosis. Tissue Antigens 2006;68:335-8.

[16] Çelmeli F, Türkkahraman D, Özel D, Akçurin S, Yegin O. CTLA-4 (+49A/G) polymorphism and type-1 diabetes in Turkish children. J. Clin. Res. Pediatr. Endocrinol. 2013;5:40-3.

[17] Kawasaki A, Tsuchiya N, Fukazawa T, Hashimoto H, Tokunaga K. Analysis on the association of human BLYS (BAFF, TNFSF13B) polymorphisms with systemic lupus erythematosus and rheumatoid arthritis. Genes Imunn. 2002;3:424-9.

[18] Shojaa M, Javid N, Amoli M, Shakeri F, Samaei NM, Aghaie M, Khashayar P, Livani S. No evidence of association between CTLA-4 polymorphisms and systemic lupus erythematosus in Iranian patients. Int. J. Rheum. Dis. 2013;16:681-4.

[19] Toure O, Konate S, Sissoko S, Niangaly A, Barry A, Sall AH, Diarra E, Poudiougou B, Sepulveda N, Campino S, Rockett KA, Clark TG, Thera MA, Doumbo O, Collaboration with The MalariaGEN Consortium. Candidate polymorphisms and severe malaria in a Malian population. PLoS One 2012;9:e43987. 
[20] Holopainen P, Naluai AT, Moodie S, Percopo S, Coto I, Clot F, Ascher H, Sollid L, Ciclitira P, Greco L, Clerget-Darpoux F, Partanen J, Members of the European Genetics Cluster on Coeliac Disease. Candidate gene region 2q33 in European families with coeliac disease. Tissue Antigens 2004;63:212-22.

[21] Pena SD, Di Pietro G, Fuchshuber-Moraes M, Genro JP, Hutz MH, Kehdy Fde S, Kohlrausch F, Magno LA, Montenegro RC, Moraes MO, de Moraes ME, de Moraes MR, Ojopi EB, Perini JA, Racciopi C, Ribeiro-Dos-Santos AK, Rios-Santos F, Romano-Silva MA, Sortica VA, Suarez-Kurtz G. The genomic ancestry of individuals from different geographical regions of Brazil is more uniform than expected. PLoS One 2011;6:e17063.

[22] Cardena MM, Ribeiro-Dos-Santos A, Santos S, Mansur AJ, Pereira AC, Fridman C. Assessment of the relationship between self-declared ethnicity, mitochondrial haplogroups and genomic ancestry in Brazilian individuals. PLoS ONE 2013;8:e62005.

[23] Vargens DD, Almendra L, Struchiner CJ, Suarez-Kurtz G. Distribution of the GNB3 $825 C>T$ polymorphism among Brazilians: impact of population structure. Eur. J. Clin. Pharmacol. 2008;64:253-6.

[24] Suarez-Kurtz G, Pena SD, Struchiner CJ, Hutz MH. Pharmacogenomic diversity among Brazilians: influence of ancestry, self-reported color, and geographical origin. Front Pharmacol. 2012;3:191.

[25] Santos NP, Ribeiro-Rodrigues EM, Ribeiro-Dos-Santos AK, Pereira R, Gusmão L, Amorim A, Guerreiro JF, Zago MA, Matte C, Hutz MH, Santos SE. Assessing individual interethnic admixture and population substructure using a 48insertion-deletion (INSEL) ancestry-informative marker (AIM) panel. Hum. Mutat. 2010;31:184-90.

[26] G. Warnes, G. Gorjanc, F. Leisch, M. Man, Genetics: population genetics, R package version 1.3.6. <http://CRAN.R-project.org/package=genetics>, 2011 (accessed 30.07.12).

[27] J.P. Sinnwell, D.J. Schaid, haplo.stats: Statistical analysis of haplotypes with traits and covariates when linkage phase is ambiguous, $\mathrm{R}$ package version 1.4.4. <http://CRAN.R-project.org/package=haplo.stats>, 2009 (accessed 29.04.13).

[28] Wickham H. Ggplot2: Elegant Graphics for Data Analysis. New York: Springer; 2009.

[29] Pedroza LS, Sauma MF, Vasconcelos JM, Takeshita LY, Ribeiro-Rodrigues EM, Sastre D, Barbosa CM, Chies JA, Veit TD, Lima CP, Oliveira LF, Henderson BL, Castro AP, Maia MH, Barbosa FB, Santos SE, Guerreiro JF, Sena L, Santos EJ. Systemic lupus erythematosus: association with KIR and SLC11A1 polymorphisms, ethnic predisposition and influence in clinical manifestations at onset revealed by ancestry genetic markers in an urban Brazilian population. Lupus 2011;20:265-73.

[30] Tarazona-Santos E, Castilho L, Amaral DR, Costa DC, Furlani NG, Zuccherato LW, Machado M, Reid ME, Zalis MG, Rossit AR, Santos SE, Machado RL, Lustigman S. Population genetics of GYPB and association study between $\mathrm{GYPB} * \mathrm{~S} / \mathrm{s}$ polymorphism and susceptibility to $P$. falciparum infection in the Brazilian Amazon. PLoS One 2011;6:e16123.

[31] The 1000 Genomes Project Consortium. An integrated map of genetic variation from 1,092 human genomes. Nature 2012;491:56-65.

[32] Liao WL, Chen RH, Lin HJ, Liu YH, Chen WC, Tsai Y, Wan L, Tsai FJ. The association between polymorphisms of B7 molecules (CD80 and CD86) and Graves' ophthalmopathy in a Taiwanese population. Ophthalmology 2011;118:553-7.

[33] Xiang H, Zhao W, Sun Y, Qian W, Xing J, Zhou Y, Yao J, Xu J, Wang Y, Yao H, Hu Z. CD86 gene variants and susceptibility to pancreatic cancer. J. Cancer Res. Clin. Oncol. 2012;138:2061-7.

[34] Liu CP, Jiang JA, Wang T, Liu XM, Gao L, Zhu RR, Shen Y, Wu M, Xu T, Zhang XG. CTLA-4 and CD86 genetic variants and haplotypes in patients with rheumatoid arthritis in southeastern China. Genet. Mol. Res. 2013;12:1373-82.

[35] Beltrame MH, Pincerati MR, Dalla-Costa R, Wassem R, Köhler KF, ChautardFreire-Maia EA, Tsuneto LT, Petzl-Erler ML. CD80 and CD86 polymorphisms in populations of various ancestries: 5 new CD80 promoter alleles. Hum. Immunol. 2012;73:111-7.

[36] Guzman VB, Morgun A, Shulzhenko N, Mine KL, Gonçalves-Primo A, Musatti CC, Gerbase-Delima M. Characterization of CD28, CTLA4, and ICOS polymorphisms in three Brazilian ethnic groups. Hum. Immunol 2005;66:773-6.

[37] Malheiros D, Petzl-Erler ML. Individual and epistatic effects of genetic polymorphisms of B-cell co-stimulatory molecules on susceptibility to pemphigus foliaceus. Genes Immun. 2009;10:547-58.

[38] Pincerati MR, Dalla-Costa R, Pavoni DP, Petzl-Erler ML. Genetic polymorphisms of the T-cell coreceptors CD28 and CTLA-4 in Afro- and Euro-Brazilians. Int. J. Immunogenet. 2010;37:253-61.

[39] Butty V, Roy M, Sabeti P, Besse W, Benoist C, Mathis D. Signatures of strong population differentiation shape extended haplotypes across the human CD28, CTLA4, and ICOS costimulatory genes. Proc. Natl. Acad. Sci. U.S.A. 2007; 104:570-5. 